\title{
The Effects of Scaffolding in the L2 Classroom: Teacher Support in Relation to Student In-class Engagement and Appreciation of Support
}

\author{
Li Yong ${ }^{1, *}$ \\ ${ }^{1}$ Graduate School of Education, University of Pennsylvania, Philadelphia, PA 19104, US \\ *Corresponding author. Email: ylcaro16@upenn.edu
}

\begin{abstract}
Second language learners, particularly those with a low language competence, often show unwillingness to communicate in the target language and engage in the class activities or tasks. Scaffolding is believed to be an effective instructional tool to foster L2 learning. Yet, few evidences can be found in previous studies on scaffolding and its influence on learner engagement in a classroom setting. This study investigated how teachers' use of scaffolding techniques impacts L2 learners' classroom engagement and appreciation of teacher support in an online ESL classroom with a mix-method approach. The participants included twenty-two Chinese immigrant L2 learners with a beginner level of language proficiency and two qualified L2 co-teachers. The study lasted for three weeks, during which students took six class sessions. Students' in-class engagement and performance were documented through class observation. Their appreciation and overall attitude towards the teacher scaffolding were revealed by answering a designed anonymous questionnaire containing nineteen statements. Results indicated that students' classroom engagement frequency experienced a notable increase after they received teacher scaffolding. Also, according to the questionnaire answers, a positive relationship was found between the teachers' use of scaffolding and students' appreciation of support.
\end{abstract}

Keywords: Scaffolding, Engagement, Appreciation of support, Second language learner, Teacher support.

\section{INTRODUCTION}

Second language (L2) learners often show unwillingness and reluctance to use the target language and engage in in-class activities or tasks, particularly those with relatively lower proficiency levels. And this might be caused by their lack of communicative competence (i.e., not having complete control of the register and discourse of the target language) and foreign language anxiety [1][2]. They may actively participate in class, for example, listening attentively to the teacher's instruction and doing choral drills. However, their participation does not equal their engagements in the language classroom. Instead of pure participations, the latter calls for learners' meaningful investment and social involvement in the instructional activities or tasks with their teachers and peers [3]. In this case, proper assistance and support should be given to novice L2 learners in the classroom to facilitate their engagement and language learning.
Scaffolding, the support tailored to students' needs, is believed to be effective in promoting L2 learning and has received sufficient attention in education research in the past few decades [4]. Yet, empirical studies on teacher scaffolding and its effect on learners' engagement and appreciation of support in a classroom setting are rare. Therefore, this study set out to fill this gap by examining whether teachers' use of scaffolding techniques could affect L2 students' classroom engagement and their appreciation of support.

\section{LITERATURE REVIEW}

\subsection{Scaffolding}

Scaffolding refers to the "practice of providing appropriate support to help learners engage in tasks that are beyond their current level of proficiency" [5]. It can also be regarded as a powerful instructional tool to help learners extend their level of understanding and complete tasks successfully [6]. This concept, 
introduced by a cognitive psychologist named Jerome Bruner in the late $1950 \mathrm{~s}$, is closely related to Vygotsky's construct of the Zone of Proximal Development (ZPD). Vygotsky defined the ZPD as "the distance between the actual development level as determined by independent problem solving and the level of potential development as determined through problem solving under adult guidance or in collaboration with more capable peers" [7]. A strong connection between scaffolding and the ZPD has been reported in the literature. For instance, Walqui argued that scaffolding only occurs within the ZPD, while Ellis held a similar position that learners construct their ZPD through scaffolding and can thereby promote learning development [1][8]. In other words, when it comes to language learning, if tasks are well designed within the learners' ZPD, then learners with proper support will achieve better language attainments than those without.

Van de Pol et al. suggested that scaffolding should be viewed as contingent support [9]. It represents a teacher's dynamic intervention that is tailored to different situations, where students might have different needs, understandings, and assigned tasks to complete. Particularly, the support provided by the teacher must be at the same or a slightly higher level of the learners' current language proficiency. Therefore, teachers should apply different scaffolding techniques regarding specific circumstances to make the task with controlled complexity and manageability at any time [10]. In 2006, Walqui presented six main types of instructional scaffolding techniques that could be applied to assist language learners' performance: modeling, bridging, contextualization, building schema, re-presenting texts, and developing metacognition [1]. Modeling refers to directly showing students what to do in the activities or tasks. Also, concrete examples should be given to them in the modeling, as they need clear guidance of what is requested for imitation. Bridging refers to the teachers' employment of learners' prior knowledge to teach new concepts and enhance engagement. Another way of bridging is asking students to share related personal experiences. This scaffolding technique is effective in that learners' understanding can be achieved by weaving new information into the existing one [11]. Contextualization refers to introducing language in meaningful contexts and with authentic objects. Building schema is combining new information with pre-existing one to help students understand the connections. Re-presenting text engages students in activities requiring them to transform linguistic constructions from one genre to another, such as converting a short story into a personal narrative. Developing metacognition means that students monitor and adjust their language learning process.

\subsection{Scaffolding, Engagement, and Appreciation of Support}

Most research on scaffolding (specifically contingent support) used learners' final language attainment as an outcome measure [4]. However, few educational studies on this topic took other outcomes such as students' in-class engagement and appreciation of support into consideration, which are essential predictors of learners' language gains as well [4][12].

In language learning, scaffolding is an effective instructional and learning strategy to enhance learners' engagement, primarily through interactive and collaborative activities [6]. Engagement refers to the behavioural intensity and emotional quality of learners' involvements when contributing to learning activities and tasks [12]. Engaged students focus on the task, make active investments, and stay positive when encountered with difficulties. In contrast, those disengaged ones seem distracted, feel hesitant and anxious to participate, and show a negative attitude towards challenges. In their study on reading instruction for elementary school students, Lutz et al. argued that teacher scaffolding led to students' greater engagement in the class activities and notable growth in their reading comprehension [3]. Moreover, investigating teachers' instructional styles and students' engagement, Jang et al. discovered that teachers' autonomy support could lead to students' behavioural engagements in class and their self-reported engagement outside of the classroom [12]. This finding is in accordance with Assor et al.'s study, where teachers' support tends to foster students' engagements in schoolwork [13].

Students' appreciation of support (i.e., their attitude towards teacher's scaffolding) is another factor in their language learning achievement [4]. Language learners who hold a favorable view towards teacher's use of scaffolding techniques will benefit from the long-term influence of teacher support to engage in future learning out of the classroom and become more capable and independent learners [14]. Though little can be found about the effect of scaffolding on learners' appreciation of support in the existing literature, this question is still worth further exploration; since learners' attitudes towards teacher scaffolding could lead to their different performances in language learning and thus result in different language outcomes. Hence, this present study aims to address the following research questions:

1. How does students' in-class engagement differ when receiving different levels of teacher scaffolding?

2. What is students' overall attitude towards the teacher's application of scaffolding? 


\section{METHOD}

\subsection{Participants}

The sampled class was a beginner-level ESL course based in Philadelphia, United States, which met twice a week (1.5 hours per session). All class sessions were moved online due to the COVID-19 Pandemic and were well-recorded with the permission of all participants and the signatures of ethical forms.

Participants in this study were twenty-two Chinese older adult immigrants aged from 59 to 78 . They joined the course to learn practical and conversational English, supporting their living in the US.

Meanwhile, this study also included two co-teachers teaching English as a second language whose first language is Chinese but uses English as the medium of class instruction. The teachers in the study were proficient in English to teach a beginner-level ESL class.

\subsection{Research Instruments}

The present research was a mixed-method observation study. For the online observation part, the researcher observed a total of 6 class sessions ( 3 weeks), documenting the students' engagement frequency (i.e., making meaningful investments) in the class activities or tasks.

The teachers appropriately designed several group activities or tasks that called for students' L2 production according to their current language proficiency level and daily needs. In the first two class sessions, the teachers provided only spoken or written instructions and documented their engagement frequency. Then, in the following four class sessions, the teachers implemented various scaffolding techniques when giving task instructions to facilitate the students. The teachers chose their instructional scaffolding techniques mainly from Walqui's classification [1]. They also applied other techniques, such as the use of visuals and simplifying the language.

On top of this, after six class sessions, students completed an anonymous questionnaire designed to collect their attitudes towards their teachers' pedagogical use of scaffolding when giving instructions. The questionnaire consisted of nineteen statements, including students' preference towards certain types of scaffolding (e.g., "I like the way my teacher directly shows me what to do in a task.") and overall feelings after receiving teacher support (e.g., "I feel myself becoming more confident in class with the instructions and help from my teacher."). Students used the fivepoint Likert scale ranging from "Strongly agree" to "Strongly disagree" to show their levels of appreciation of teacher support.

\section{RESULTS AND DISCUSSION}

\subsection{In-class Engagement}

Based on class observations, the researcher documented the participants' engagement frequency and class performance and investigated whether students' engagement differs when receiving different levels of scaffolding. The result showed a notable increase in students' engagement in the class activities or tasks after receiving teacher scaffolding support (see Figure 1).

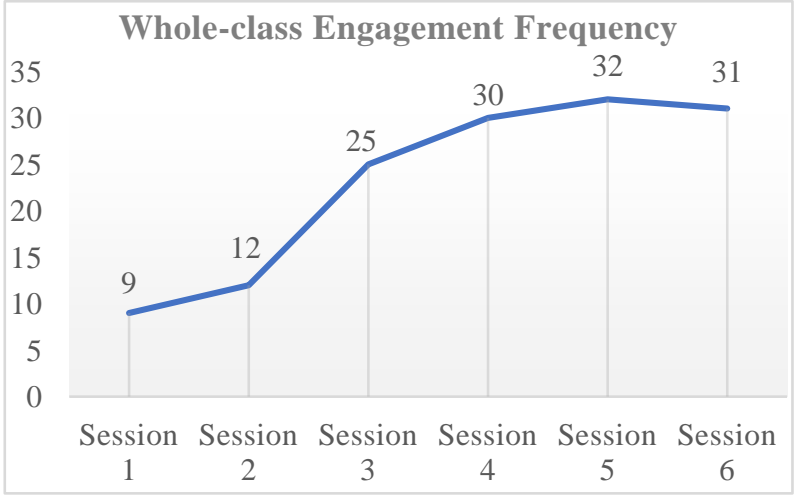

Figure 1 Whole-class Engagement Frequency.

In the first- and second-class sessions where the teachers only provided spoken or written instructions in complete sentences, the whole class engagement frequency was 9 and 12 times, respectively. Less than half of the students were actively involved in the class activities or tasks and used the target language for production. In contrast, others kept silent in class and relied heavily on their first language (L1) to interact with their teachers and peers. However, things changed after the teachers applied scaffolding techniques such as modeling, contextualization, and bridging. The whole class engagement frequency witnessed a 108.3\% remarkable and surprising growth in the third-class session with a frequency of 25 times. That meant nearly all participants made meaningful investments in the class activities for at least one time. Students' sharing of their original ideas, negotiating the group task with partners, and commenting on others' work were observed in the online classroom. In the following three class sessions, the students' engagement frequency experienced a slight increase and then remained stable around 30 .

Meanwhile, changes in engagement frequency of those extremely reticent individuals in the class could be taken as more substantial evidence to prove the effectiveness of scaffolding. For instance, a participant named Hiu kept silent in class for the first three class sessions. Starting from the fourth-class session, he began engaging in the activities by negotiating answers in L2 with his group members in a Jeopardy game (see Figure 2). He later commented that the jeopardy game 
designed by the teachers was of great fun and with manageable rules for novice L2 learners like him.

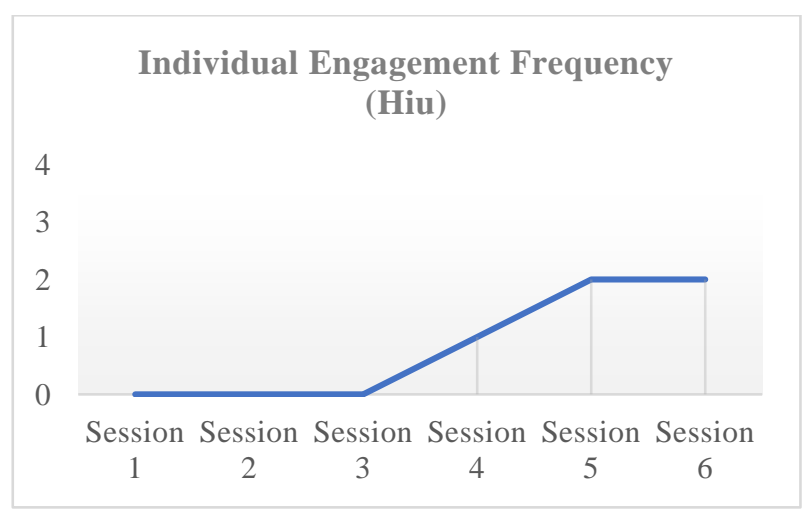

Figure 2 Individual Engagement Frequency (Hiu).

The findings above demonstrated that the teachers' use of scaffolding techniques could effectively lead to better engagement in the language classroom. Nevertheless, teacher support which functions as a facilitator (i.e., a causal factor) for engagement, cannot solely maintain students' engagement at the same level. As time goes by, students may become more and more disengaged in class for different reasons, such as losing interest [15]. Hence, proper attention should also be given to the indicators of classroom engagement, which refer to the features that lie inside the concept of engagement [15].

Several researchers believe that successful and highquality learning is a consequent result of learners' behaviours and emotions. Of these two engagement indicators, the emotional dimension will be the discussion focus because the participants in this study are all strongly motivated and attentive in class and have made persistent efforts to learn the language (which belongs to the behaviour dimension of engagement). The emotional dimension of classroom engagement includes students' emotional involvement in the instructional interactions or class activities such as enjoyment, satisfaction, and interest. These positive emotions are found effective in fuelling student engagement [16]. Therefore, a possible explanation for the study participants' sudden changes in their class behaviour might be the emotional changes that led to their promoted engagement. Hiu's comments on the jeopardy game ("of great fun" and "manageable") which revealed his interest, enjoyment, and confidence in the class activity, were strong evidence.

\subsection{Appreciation of Support}

Students' Likert-scaled answers to the statements in the designed questionnaire were collected to answer the second research question. To explore students' appreciation of teacher scaffolding, the nineteen statements in the questionnaire consisted of three types: students' preference towards certain types of scaffolding techniques, students' feelings and after receiving teacher support, and their evaluation of teachers' employment of scaffolding in the classroom.

Results indicated an overall positive attitude towards teacher support. Firstly, of the eight listed scaffolding techniques teachers used when giving activity or task instructions, using simplified language (100\%), modeling $(86.36 \%)$, and providing concrete examples $(77.27 \%)$ were the three most favored techniques by those beginner-level learners. While students showed apparent appreciation for seven of the eight techniques, divergence occurred in the statement, "I like the way my teacher tells me what to do in a task all at once." $50 \%$ of the participants chose "strongly agree" or "agree". About $9 \%$ stood in the neutral, and about $41 \%$ of them, to some extent, disagreed with this statement. This difference showed that some individuals tend to receive and process information gradually while others may prefer doing this faster.

Secondly, when it came to students' personal feelings after being assisted by teacher scaffolding, nearly $90 \%$ of the participants claimed that they felt more active, more encouraged, more contributed, and more confident in getting involved in the class activities and accomplishing the tasks. One notable finding was that even with the facilitation of teacher scaffolding, some students were still experiencing anxiety (18.18\%) and reluctance $(13.63 \%)$ to engage in the language learning activities (see Table 1). Thirdly, all participants positively evaluated teacher scaffolding, confirming its effectiveness in remembering and internalizing the class contents and improving their L2 learning.

Table 1. Students' personal feelings for scaffolding

\begin{tabular}{lll}
\hline Feelings & $\begin{array}{l}\text { Less } \\
\text { Anxious }\end{array}$ & Less Hesitant \\
\hline Strongly & $\mathrm{O}$ & $13.63 \%$ \\
Agree & & \\
Agree & $68.18 \%$ & $63.63 \%$ \\
Neutral & $13.63 \%$ & $29.09 \%$ \\
Disagree & $18.18 \%$ & $13.63 \%$ \\
Strongly & 0 & 0 \\
Disagree & &
\end{tabular}

Students' appreciative attitudes towards the teachers' implementation of scaffolding techniques revealed a positive relationship between contingent support (i.e., scaffolding) and appreciation of support in a classroom setting. However, facilitated by teacher scaffolding, some participants still felt anxious and hesitant to engage in the L2 activities and produce the target language. It seemed possible that this circumstance was due to the students' foreign language anxiety. MacIntyre and Gardner defined language anxiety as the feeling of tension and agitation connected with second language contexts, including speaking, listening, and learning [17]. The findings of Liu and Jackson's research on Chinese EFL learners' unwillingness to communicate in 
L2 demonstrated that low L2 proficiency and language anxiety were the two reasons why learners did not like to risk using English in the classroom [2]. They felt anxious because they were afraid of being negatively evaluated when speaking the target language. In this case, to reduce learners' foreign language anxiety and enhance their use of L2, language teachers should create a less stressful learning environment for the students to complete the tasks without fear and anxiety [6]. One of the ways to achieve this might be providing students with more interactive group activities, where sufficient opportunities for engagement and learning are contained [1]. Especially, L2 learners with low understanding and proficiency could have better chances to learn through interaction with their peers [6].

\section{CONCLUSION}

The results from the present study have therefore illustrated that the teachers' use of scaffolding techniques in the classroom can have a positive impact on students' in-class engagement and is positively related to students' appreciation of teacher support. Also, students' classroom engagement should be recognized as a complex status that needs to consider learners' cognitive, behavioral, affective, and social involvements in the class activities. These findings could have pedagogical and learning implications for both second language teachers and learners. For L2 teachers, since contingent support could result in improved student performances, they should consider students' needs, learning styles, and task types when choosing the most appropriate instructional scaffolding technique [4]. Moreover, L2 teachers should be given chances to learn how to scaffold their students to increase their contingency in the classroom. For L2 learners, being aware of teachers' scaffolding could help them learn how to use the techniques themselves. Thus, mutual scaffolding among peers may occur during the class interactions and assist learners' mutual discovery and construction of new knowledge while promoting their self-regulation and independence for L2 learning outside the classroom [18].

This research has provided new insights into the relationship between teacher scaffolding and student engagement in an ESL classroom, particularly beginnerlevel Chinese older adult immigrants. Yet, as a smallscale mix-method study with a time limit of only three weeks, it is essential to be cautious about generalizing the above results to all L2 learning groups with different language competencies and learning motivations. Moreover, in terms of student's in-class engagement measures, the study relied heavily on the researcher's observations, which may decrease the objectivity of data. Hence, future researchers should lengthen the experiment time to increase the reliability of data collected and resort to a more validated evidence-based engagement measurement to explore learners' classroom engagement further.

\section{REFERENCES}

[1] Walqui, A. (2006). Scaffolding instruction for English language learners: A conceptual framework. International Journal of Bilingual Education and Bilingualism, 9(2), 159-180. https://doi.org/10.1080/13670050608668639

[2] Liu, M., \& Jackson, J. (2008). An exploration of Chinese EFL learners' unwillingness to communicate and foreign language anxiety. The Modern Language Journal (Boulder, Colo.), 92(1), 71-86. https://doi.org/10.1111/j.15404781.2008.00687.x

[3] Lutz, S., Guthrie, J., \& Davis, M. (2006). Scaffolding for engagement in elementary school reading instruction. Journal of Educational Research, $\quad 100, \quad 3-20$. https://doi.org/10.3200/JOER.100.1.3-20

[4] Van de Pol, J., Volman, M., Oort, F., \& Beishuizen, J. (2015). The effects of scaffolding in the classroom: support contingency and student independent working time in relation to student achievement, task effort and appreciation of support. Instructional Science, 43(5), 615-641. https://doi.org/10.1007/s11251-015-9351-z

[5] Zhang, M., \& Quintana, C. (2012). Scaffolding strategies for supporting middle school students' online inquiry processes. Computers and Education, $\quad$ 58(1), 181-196. https://doi.org/10.1016/j.compedu.2011.07.016

[6] Yildiz, Y., \& Celik, B. (2020). The use of scaffolding techniques in language learning: Extending the level of understanding. International Journal of Social Sciences \& Educational Studies, $7(3)$, 148-153. https://doi.org/10.23918/ijsses.v7i3p148

[7] Vygotsky, L. (1978). Mind in society-the development of higher psychological processes. Cambridge: Harvard University Press.

[8] Ellis, R. (2003). Task-based language learning and teaching. Oxford: Oxford University Press.

[9] Van de Pol, J., Volman, M., \& Beishuizen, J. (2010). Scaffolding in teacher-student interaction: A decade of research. Educational Psychology Review, 22(3), 271-296. https://doi.org/10.1007/s10648-010-9127-6

[10] Wood, D., \& Wood, H. (1996). Commentary: Contingency in tutoring and learning. Learning and 
Instruction, 6, 391-397. doi:10.1016/09594752(96)00023-0.

[11] Tharp, R., \& Gallimore, R. (1988). Rousing minds to life: Teaching, learning, and schooling in social context. Cambridge: Cambridge University Press.

[12] Jang, H., Reeve, J., \& Deci, E. (2010). Engaging students in learning activities. Journal of Educational Psychology, 102(3), 588-600. https://doi.org/10.1037/a0019682

[13] Assor, A., Kaplan, H., \& Roth, G. (2002). Choice is good, but relevance is excellent: Autonomyenhancing and suppressing teacher behaviours predicting students' engagement in schoolwork. British Journal of Educational Psychology, 72(2), 261-278.

https://doi.org/10.1348/000709902158883

[14] Pratt, M., \& Levine, K. (1998). Contingent tutoring of long-division skills in fourth and fifth graders: Experimental tests of some hypotheses about scaffolding. Journal of Applied Developmental Psychology, 19(2), 287-304. https://doi.org/10.1016/S0193-3973(99)80041-0

[15] Skinner, E., Furrer, C., Marchand, G., \& Kindermann, T. (2008). Engagement and disaffection in the classroom. Journal of Educational Psychology, 100(4), 765-781. https://doi.org/10.1037/a0012840

[16] Meyer, D., \& Turner, J. (2002). Discovering Emotion in Classroom Motivation Research. Educational Psychologist, 37(2), 107-114. https://doi.org/10.1207/S15326985EP3702 5

[17] MacIntyre, P., \& Gardner, R. (1994). The subtle effects of language anxiety on cognitive processing in the second language. Language Learning, 44(2), 283-305. https://doi.org/10.1111/j.14671770.1994.tb01103.x

[18] Guerrero, M., \& Villamil, O. (2000). Activating the ZPD: Mutual scaffolding in L2 peer revision. The Modern Language Journal (Boulder, Colo.), 84(1), 51-68. https://doi.org/10.1111/0026-7902.00052 